\title{
FLIPPING A MATHEMATICS COURSE, A BLENDED LEARNING APPROACH
}

\author{
Ana Paula Lopes ${ }^{1}$, Filomena Soares ${ }^{2}$ \\ ${ }^{1}$ Polytechnic of Porto (P.PORTO) / ISCAP - CEOS.PP (PORTUGAL) \\ ${ }^{2}$ Polytechnic of Porto/ESHT - ESMAD/CITH - UniMAD (PORTUGAL)
}

\begin{abstract}
Flipped classroom pedagogy has become popular in several different courses in Higher Educational Institutions (HEI). Important advantages being the increased level of lecturer and student interaction, which can have a strong impact on students' motivation, engagement, satisfaction and performance. A flipped based experiment was implemented in 2015-2016 and 2016-2017 in a Mathematics Course, at the Institute of Accounting and Administration of Porto (ISCAP), using Moodle quizzes reinforced by in-class activities and support via PowerPoint with audio support, YouTube tutorial videos and online reading materials before and after classes. In this new organizational design for the teaching and learning paradigm, as its name transmits, there was pedagogical switch of the traditional academic procedure as students' first contact with the subjects and themes was made outside the "four wall classroom bounds". Teachers' role was transposed into a kind of guide and facilitator, indicating the way to go, avoiding to walk in a parallel path, or even ahead, but indicating the way to go, motivating students in their own knowledge construction, letting them lead the way, following and supporting, constantly and carefully monitoring their learning outcomes, only interfering in the learning process as an anchor where students can rely, adjusting the right paths when they seem to deviate from the predefined learning goals. Classroom time was consumed with open discussions, solving tasks and application problems, clarifying the supporting fundaments, in order to improve students' engagement into their learning process in a collaborative environment. The operational stages and procedures will be described and, additionally, several results obtained during its implementation will be presented.
\end{abstract}

Keywords: Mathematics; Flipped Classroom; Higher Education; Blended Learning; Video Lectures.

\section{INTRODUCTION}

Information and communications technology (ICT) have become an integral part of the teaching/ learning process in academic courses at Higher Education Institutions (HEI), opening the way for the emergence of different pedagogical models like e-Learning. Blended Learning and the Flipped Classroom. The flipped classroom method or model, was developed by Jonathan Bergmann and Aaron Sams in 2000 [1], the pioneers of this "movement" (chemistry teachers, at Woodland Park High School in Colorado at that time) who, in an attempt to counter the effects of student's high absenteeism levels, began to record their lessons and post them online, allowing students to access them remotely. Therefore, the principal idea comes from reversing the traditional teaching paradigm, where the main phases of the teaching and learning process such as classroom activities and homework are reversed. The flipped classroom is then settled as a different course organization: where instructional content (e.g., pre-recorded video lectures) is assigned as "homework" - analyzed before coming to class - and in-class time is spent working on problems, advancing concepts, and engaging in collaborative learning [2]. The flipped classroom may contain a big array of out-of-class activities further than lectures, including readings, homework, and supplemental videos ([3], [4], [5]). With this pedagogical teaching methodology, as theoretical/supporting materials must be delivered as a "pre-class" tool for students to take and analyze individually, it is extremely important to examine what "kind" of materials promote students' engagement, as they must be responsible for class preparation. In this sense, with all these inherent changes, instructors have been required to adapt fast to this reality, creating and developing a substantial diversity of tools and resources to grab student's attention and to motivate them to support the knowledge in their own learning process enthusiastically. One of the most engaging resources is the use of video lectures since, through them, instructors can provide multifaceted information to students and, if used creatively, videos are a powerful technological tool in the global and self-enrolment educational process [6]. In-class activities become substantially different, including activities such as role-play, debates, quizzes, and group presentations, amongst others [7]. In addition, the flipped classroom model allows the learners to learn at their own pace [8]. On the outcome of their experience, Lopes \& Soares [9] have shown how 
Flipped Classroom leads (if properly designed/evaluated) to improve teaching-learning relationships producing a greater involvement and commitment of the students and a higher motivation as well.

The main purpose of this paper is to present an experimental study, using flipped classroom model as a pedagogical strategy to support Blended Learning - "learning that combines characteristics of both traditional and online education in integrated model, and gain the maximum benefit from the available techniques apiece" (Milheim, 2006, 44) [10] - in an attempt to obtain some fruitful answers to the question: Will the use of this Flipped Classroom methodology improve students' achievement in Mathematics?

\section{BACKGROUND}

\subsection{Blended Learning Model}

Based on a brief analysis through the available literature, there does not seem to be a clear and unambiguous definition from the concept of Blended Learning ([11], [12]). Definitions are moderately exclusive and sometimes contradictory, and there are few common terms used regularly. It is not easy to distinguish the term "blended learning" from other terms such as "virtual learning", "distance learning", "network learning", "online learning", "Web-enhanced learning", "Internet-enabled learning", among others. In Bonk and Graham [12] opinion, this model is a learning process based on a combination of traditional class and activities in an online educational environment using elements of asynchronous and synchronous distance learning. According to them the most commonly definitions are the combination of:

- instructional modalities or delivery media and technologies (traditional distance education, Internet, Web, Video/audio, any other electronic standard, e-mail, online books, etc.);

- instructional modalities, learning theories, and pedagogical dimensions;

- e-learning with face-to-face learning.

In a blended learning course, for instance, students might attend a class taught by a lecturer in a traditional classroom setting, while also individually carrying out online components of the course outside of the classroom.

The generalized idea for Blended Learning models seems to be around the reduction of classroom lessons number, moving some lessons to an online environment.

\subsubsection{Blended Learning Models}

Seven different blended learning models can be considered, according to [13].

\section{Station Rotation}

This model allows students to rotate through stations on a fixed schedule, where at least one of the stations is an online learning station. This model is most common in elementary schools because instructors are already familiar rotating in "centers" or stations.

\section{Lab Rotation}

This model permits students to rotate through stations on a fixed schedule. However, in this case, online learning occurs in a dedicated computer lab. This model allows for flexible scheduling arrangements with teachers and other paraprofessionals, and enables schools to make use of existing computer labs.

\section{i Individual Rotation}

The Individual Rotation model allows students to rotate through stations, but on individual schedules set by a teacher or software algorithm. Unlike other rotation models, students do not necessarily rotate to every station; they rotate only to the activities scheduled on their playlists. 
The Flipped Classroom model flips the traditional relationship between class time and homework. Students learn at home via online coursework and lectures, and teachers use class time for teacherguided practice or projects. This model enables teachers to use class time for more than delivering traditional lectures.

\section{Flex}

The Flex model lets students move on fluid schedules among learning activities according to their needs. Online learning is the backbone of student learning in a Flex model. Teachers provide support and instruction on a flexible, as-needed basis while students work through course curriculum and content. This model can give students a high degree of control over their learning.

\section{A La Carte}

The A La Carte model (Self-Blend model) enables students to take one or more courses entirely online with an online teacher of record and at the same time continue to have other face-to-face courses, which often provides students with more flexibility over their schedules. A La Carte courses can be a great option when schools can't provide particular learning opportunities, such as an Advanced Placement or elective course, making it one of the more popular models in blended high schools.

\section{Enriched Virtual}

This model is an alternative to full-time online school that allows students to complete the majority of coursework online at home or outside of school, but attend school for required face-to-face learning sessions with a teacher. Unlike the Flipped Classroom, Enriched Virtual programs usually don't require daily school attendance; some programs may only require twice-weekly attendance, for instance.

\subsection{Flipped Classroom Model}

The Flipped Classroom Model is an incipient learning model which purposes to increase students' active learning, collaboration and support during the learning process, through a better allocation of teaching time [1]. In particular, this model suggests that teaching time within the face-to-face school sessions should not be spent on teachers' lecturing, but instead should be invested to provide students with exceptional learning experiences within collaborative activities with their classmates as well as receiving scaffolding by their instructor [14].

The Flipped Learning Network [15] suggests the following definition for Flipped Learning:

"Flipped Learning is a pedagogical approach in which direct instruction moves from the group learning space to the individual learning space, and the resulting group space is transformed into a dynamic, interactive learning environment where the educator guides students as they apply concepts and engage creatively in the subject matter" (p. 1). Bishop and Verleger [16] defined the flipped classroom model as "an educational technique that consists of two parts: interactive group learning activities inside the classroom, and direct computer-based individual instruction outside the classroom" (p. 5). For all intents and purposes, the flipped classroom model (see Fig. 1) consists of some form of preclass activity (e.g., viewing videos) before class meetings and complete individual or group activities during face-to-face lessons [17]. Some of these activities use smartphone apps, tablets, think pairand-share activities and online formative assessments, with the objective of providing immediate feedback concerning misconceptions or gaps in students' knowledge. However, according to some authors ([9], [18], [19]), there is no standard practice for the flipped classroom approach. There are many different approaches to in-class activities, which may include a combination of small quizzes at the beginning of lessons, reviews of video lectures, small-group or large-group discussions, student presentations, application projects, etc. Some lecturers still keep in-class time for traditional lecture, based instruction in their flipped courses. Although the variation of learning activities in the classroom, lecturers consider that the diversity of these activities is in accordance with the flipped classroom approach. 


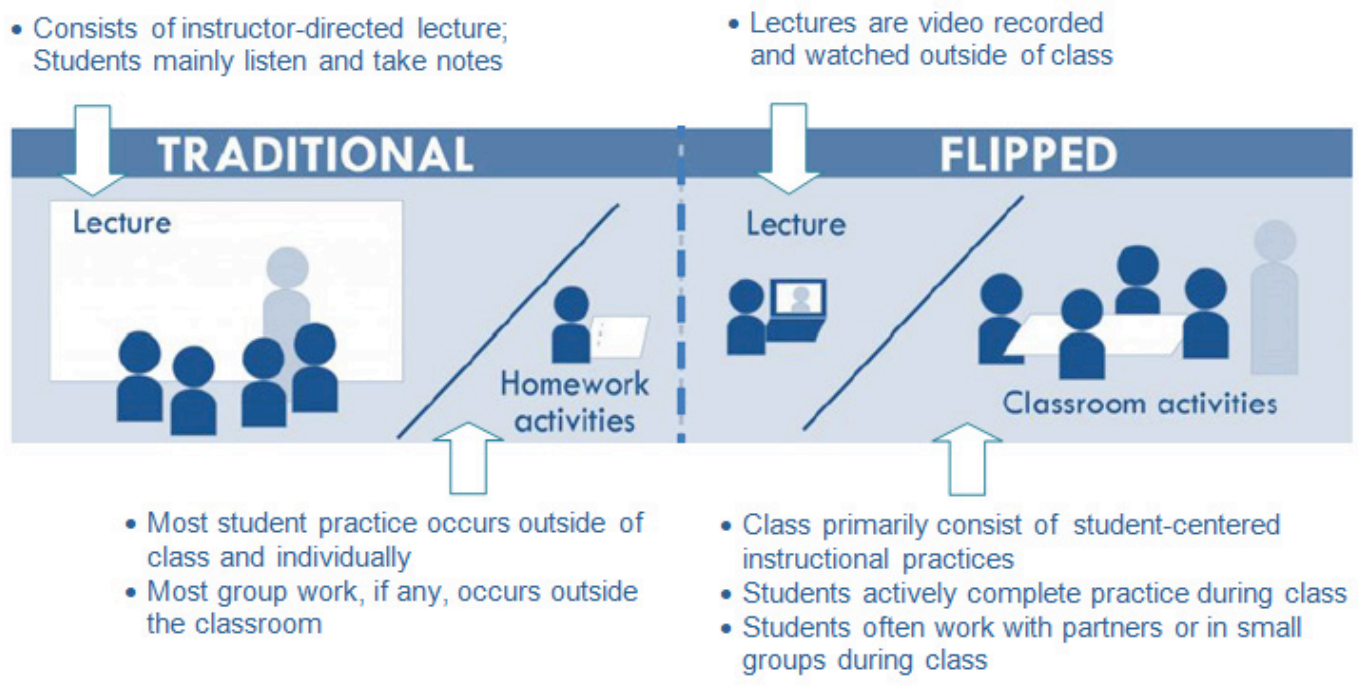

Figure 1. Flipped Model versus Traditional Classroom (Adaptation from [14]).

In 1956, the cognitive psychologist Benjamin Bloom [20] made public his famous Taxonomy of Educational Objectives, commonly known as Bloom's Taxonomy, developed for classifying learning objectives in levels. Bloom's classification included three areas of learning: cognitive, affective and psychomotor. In his framework, he divided cognitive domain into six levels or categories, ranked from the simplest and most concrete to the more complex and abstract: knowledge, comprehension, application, analysis, synthesis and evaluation. The first three levels correspond to concrete thinking, while the top three fall into the field of creative and abstract thoughts. Anderson \& Krathwohl [21] revised Bloom's original Taxonomy that resulted in the so-called Revised Bloom Taxonomy (RBT). In this review, the categories were divided as follows: remember, understand, apply, analyze, evaluate and create. In contrast to the original taxonomy, here the choice relied on verbs rather than nouns, since these better reflect the active nature of the learning process. At home, with the student's preliminary study, they would work the first three areas from RBT - remember, understand, apply while in class more complex levels can be approached - analyze, evaluate and create (Fig. 2). Therefore, the lecturer becomes a guide in the learning process while the student becomes the center of it, thus having an active role.

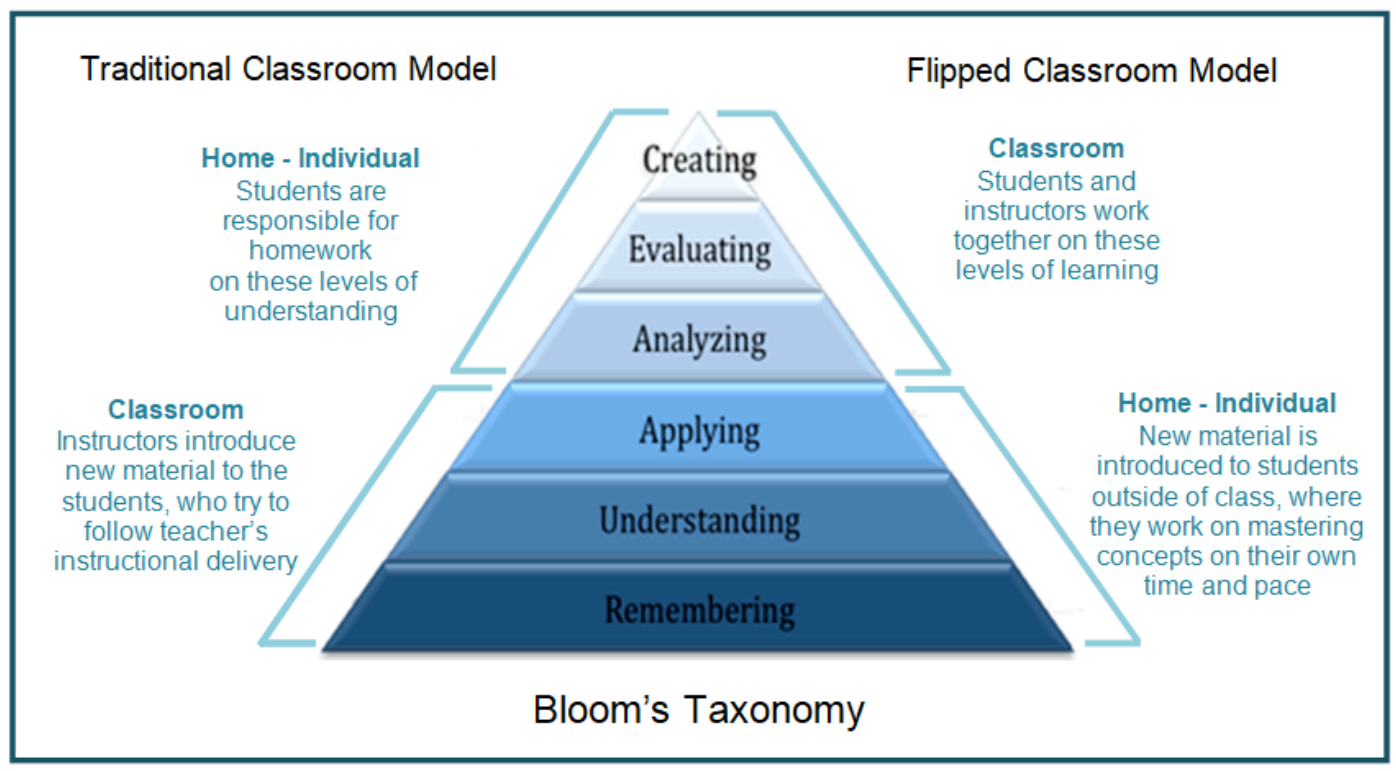

Figure 2. Connection between Traditional and Flipped Classroom to Bloom's Taxonomy. 


\subsection{P.PORTO Online Mathematics Projects}

All over the world, many students struggle when it comes to learning Mathematics. Researchers and instructors all around the world suggest different methods, technics and models to learn mathematics [22]. Having some background experience, given by the participation on some Mathematics Projects developed at Polytechnic of Porto (P.PORTO), namelly:

- MatActiva Project - an Online Mathematics Education Project which aims to support and enhance mathematics education, a kind of personalized learning platform in which students can learn at their own pace several Math subjects ([23], [24], [25]);

- Math Without STRESS (M100S) Project - a Massive Open Online Courses (MOOC), which consists of two different Courses, Probability and Combinatorics and Introduction to Differential Calculus ([26], [27],[28]);

\subsubsection{MatActiva Project}

Based on educational teaching and learning principles, this project is, at the present, used for blended learning, distance education and flipped classroom in ISCAP, making use of its several sections.

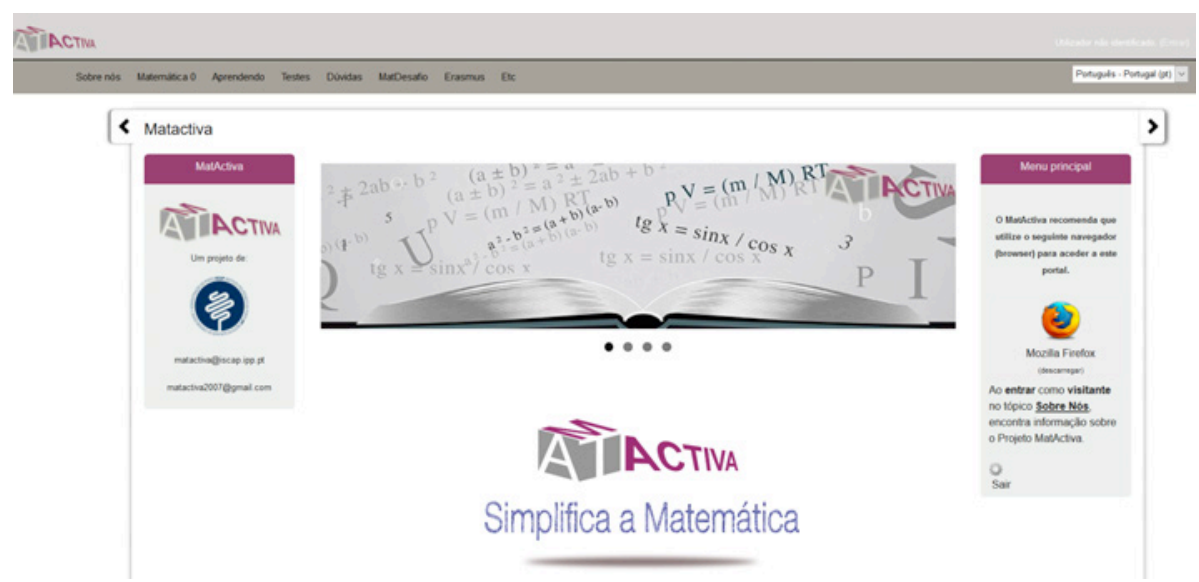

Figure 3. Screen Shot of http://paol.iscap.ipp.pt/matactiva/ (16/01/2018).

We have been concerned in creating a project of simple access, intuitive and with a set of useful functionalities. The MatActiva project is structured in eight sections and each section contains diversified material ranging different students' needs and levels of knowledge. Among other areas, we can find different resources in Linear Algebra, Financial Calculus, Statistics and Mathematical Analysis. Among other, students may find:

- Theoretical elementary notes that help to consolidate necessary requirements to all the courses from mathematics area;

- Syllabus - Program Contents covered in Mathematics Zero (MZ) (items from Elementary and Secondary school);

- Tutorial Video Lectures about several Mathematics subjects, followed by exercises that can be performed online, in which the student automatically receives the quantitative results, the feedback for each question and a proposal for a comprehensive solution;

- Diagnostic tests - with several levels, according to the Elementary and Secondary Education programs, that can be done online. They offer quantitative results and respective feedback to the student which may have, automatically, a perception of their level of performance. Students still have access to a draft solution step by step (currently $M Z$ Issues Base has over 350 questions).

- Links to external webpages with mathematical resources that explore the different contents in Mathematics.

- A set of multiple choice tests, true/false and matching. With these tests we intend to offer to students, working instruments to promote self-regulation of their learning in order to help raise 
the level of their performance. A Question Pool was created from the ground up, grouped into categories and subcategories:

- Algebra (261 questions

- Statistics (298 questions)
- Mathematical Analysis (325 questions)

- Financial Mathematics (279 questions)

The combination of questions in each category is randomized and it generates a high number of different tests that students can solve online, wherever they are and at a time that suits them. The tests allow multiple attempts, providing automatically quantitative results and each attempt corrected immediately. For each wrong answer presents a feedback with a suggestion of a solution step by step, so that the student will be able to identify what went wrong with his answer, offering and promoting self-assessment moments of mathematical knowledge and skills.

\subsubsection{Math Without STRESS (M100S) Project}

"Mathematics without STRESS" (or in its original version - in Portuguese - Matemática 100 STRESS) was the first MOOC launched by P. Porto, for incoming HE students to prepare them for post-highschool courses using mathematics. This MOOC consists of three different Courses: Probability and Combinatorics, Introduction to Differential Calculus and Trigonometry and Complex Numbers. All these courses are created using the same guidelines based on the following division:

- Information Spot

- Math Diagnostic Test (MDT) - entry test, not mandatory;

- Modular subject division with two distinct subsections:

- Video-lectures

- Sequential mini-quizzes;

- "Doubt Ed" - Open Discussion forum;

- Final "Assessment Test"

- Global Course evaluation

The first course - Probability and Combinatorics (PC) - embraces 19 different modules/lessons, with 19 randomized quizzes and 24 video-lectures, distributed by the following topics:

- Random Experiment and Sample Space

- Probability and Properties of Probability

- Conditional Probability

- Law of Total Probability and Bayes Theorem

- Fundamental Counting Principle

- Arrangement without repetition

- Permutations

- Pascal's Triangle

- Probability Distribution

- Normal Model.
- Events and Operations on Events

- Exclusive Events

- Intersection Events

- Independent Events

- Factorial of a Natural Number

- Arrangement with repetition

- Combinations

- Newton's Binomial Formula

- Binomial Model

The second course - Introduction to Differential Calculus (IDC) - comprises 18 randomized quizzes and 65 video-lectures, separated in the following topics:

- Basic Calculus review

- Understanding functions

- Exponential Function

- Function Limit Theory

- Asymptotes

- Derivative Applications
- Polynomials Review

- Polynomial, Rational and Irrational Functions

- Logarithmic Function

- Function Continuity

- Function Derivative

- Second Derivative and Applications 
As we have already mentioned, all modules have similar structure, they present an ordered set of video lectures where the relevant concepts are exhibited along with some illustrative examples. After watching each video (playing and replaying it as many times as they please), students can take a small quiz, with 5 random questions, and apply the concepts addressed in video lectures. In relation to these small quizzes, students can have multiple attempts at each one of them. This can help to transform the quiz taking process into an educational activity instead of a simple assessment. As the quiz is randomized, the student will get a new version in each attempt, which will be useful for practice purposes. Feedback is provided for each question, allowing the students to see one (of the possible) proposed solution, step by step. The Pool of Questions, from which the quizzes are randomised, is categorized separately by learning items (modules), as well as subdivided in difficulty levels.

\section{METHODOLOGY}

This study is being carried out, as a different approach to the teaching/learning process in Mathematics, at a Higher Education Institution. This was implemented in 2015-2016 and 2016-2017 in a Mathematics Zero Course (MZC), at ISCAP, supported by two online Math projects developed at the Polytechnic of Porto (P. Porto): "Mathematics without STRESS - MOOC" and MatActiva Project. The sample of our study consisted of a total of 89 students, 15 students enrolled in 2015/2016 and 22 students in 2016/2017, who attended to MZC from Zero Year Course. The participants' age ranged between 18 and 23 years old. Three modules/sections of Mathematics: Probability and Combinatorics; Introduction to Differential Calculus; and Trigonometry and Complex Numbers, were taught during the academic year. The modules Probability and Combinatorics and Introduction to Differential Calculus, were taught by using the flipped classroom model, while the topic Trigonometry and Complex Numbers was taught by traditional teaching methods.

The flipped classroom lesson was scheduled one day per week for 90 minutes per lesson. Students of the flipped class were required to view one to six short lecture videos, each lasting between five to eight minutes, prior to the class meeting. The theory and examples found in the video lectures were similar to those presented in the lecture classes. The video-lectures for M100S course can be found in [29]. Although these were short (8 minutes maximum), we introduced, in several ones, a small group of questions and exercises, to be answered by students before continuing the video visualization in order to create some interaction, promote student engagement and, simultaneously, help them to overcome the tendency to be overconfident in their learning judgment (see some research results in [27]). Frequently, at the beginning of the class we straightly answered several questions related to an item in the video, but a lecture was never taught by the professor in the class. Online quizzes and activities were combined to "test" what students have learned. Instantaneous quiz feedback and the ability to repeat lecture segments helped them to clarify some "grey" points in their minds. Inside classroom, students put into practice what they have learned from the video lectures and many other resources they previously came across, collaborating and creating meaningful work, developing some tasks through several discussions with the instructors' supervision and guidance. During the flipped classroom meeting, additional problems were worked in small groups, and the professor observed and supported student participation and progress, corrected students if errors were seen, and answered questions as they arose. The mentioned quizzes can also enhance learning because if students are "tested" prior to class, we have the additional opportunity to use feedback from these tests to tailor the content addressed in class time. Once a module was completed, students had a test with questions related to theory and examples covered during the lectures.

With this research, we intend to examine whether the introduction of this flipped model improved the learning experience according to the students' perception.

\section{RESULTS}

At the end of each teaching module when graded, an anonymous survey was given to students. Each survey included three sections: Section1, a numerical rating was used to evaluate the improvement of students' mathematical knowledge and skills (a 5 point Likert scale, was used, where "1" represented Very Unlikely and "5" represented Very Likely); Section 2, a numerical rating was designed to evaluate the effectiveness of the flipped classroom approach in facilitating students' learning; and in Section 3 , a written feedback was required, which included two open-ended questions which asked students to list the aspects they liked about the flipped classroom teaching approach and provide suggestions for further improvement. The questions in Section 1 (Fig. 4) were designed to evaluate the effectiveness of these teaching videos and Quizzes practice to enhance students' knowledge in solving problems 
from both modules. In these questions, it is hypothesized that the M100S and MatActiva teaching modules enhance students' understanding of knowledge learned in this course; on the other hand, the questions were also used to evaluate the improvement in students' Mathematics skills to solve Probability and Differential problems. The students were asked to compare their mathematical knowledge and skills before and after viewing the teaching modules. The comparison results were then used to evaluate the teaching effectiveness of the implemented flipped classroom model. Section 2 (Fig. 4) includes questions on the effectiveness of the flipped classroom model to improve students' overall learning and ability to solve Mathematics problems.

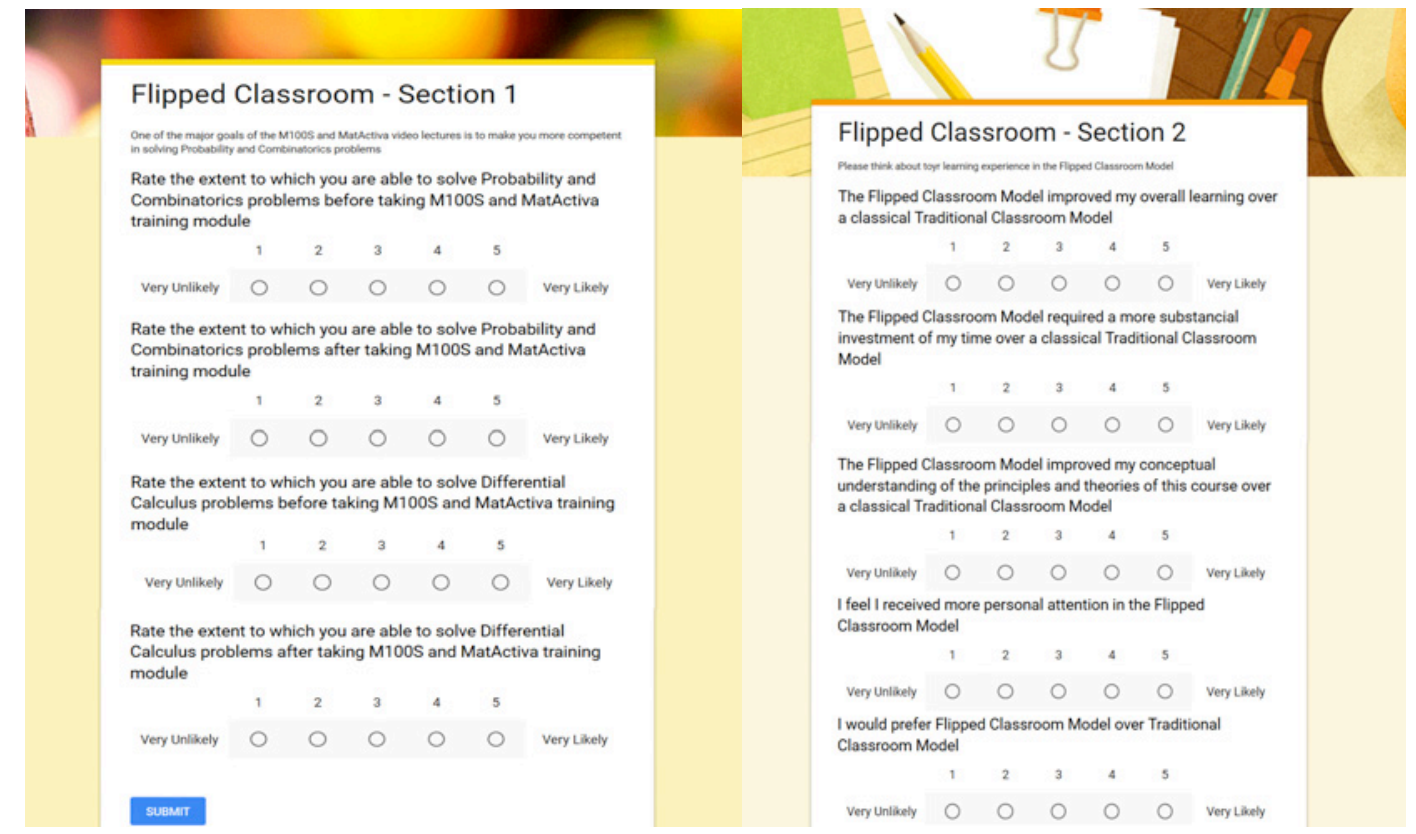

Figure 4. Screen Shot of the surveys - Section 1 and Section 2.

The results indicate that, students' Probability and Differential Calculus knowledge taught in the MZC was improved after they took the teaching modules. The average of student's performance levels before taking the training modules was around or below 2 out of 5 , while after they took the training modules the average rose to above 4 out of 5 . This means that the implementation of this model can enhance students' performance in Mathematics. The students' answers, in Section 2, suggest that they gradually adapted to the flipped classroom model after they got more and more familiar with this model.

In Section 3, students were requested to give their opinion on their experience in the flipped MZC and provide recommendations for further improving the teaching modules. The features students liked the most in this model were: the opportunity to watch the videos repeatedly at the time and pace they felt comfortable with (around $82 \%$ of students); the fact that the instructor was able to answer their questions immediately in class (around $73 \%$ of students); the alternative chance offered by videolectures to understand the concepts introduced in the in-class format (around $87 \%$ of students); the online exercises, with solution step by step, helped them gain solid knowledge and skills in Mathematics (around $85 \%$ of students).

\section{CONCLUSION}

The use of a flipped classroom approach encourages both students and professors to rethink how learners learn and professors teach. The embracement of new teaching methods, course designs, and technology allows more flexibility for all $\mathrm{HEl}$ agents and addresses the needs of students with differing learning styles. From the lecturer point of view, teaching in flipped classroom courses may be, at the beginning, uncomfortable as it demands a complete role shift from presenter to facilitator. These challenges also include a huge increased in the time spent in course preparation to find and/or create quality online resources, since it is not an easy or hasty task to create learning activities that foster student interaction and active learning. We cannot fail to mention that, initially, students may resist to 
this method of learning and not putting the time required outside classroom, having some difficulty in completing the necessary preparation for in-class activities.

However, it is the belief of the authors that the strengths of this model prevail over the concerns and extra work. Flipped classroom model as a Blended Learning approach allows flexibility in the proportion and timing of online versus face-to-face interaction which give to the lecturer the flexibility to meet the needs of the HEl, the course and the students.

We proposed a flipped classroom approach for teaching Probability and Combinatorics and Differential Calculus to the students of a Mathematics Zero Course. These two modules containing 37 randomized quizzes, with hundreds of questions, were designed and 89 video-lectures, created from scratch, were employed. Three student surveys were conducted separately for all the teaching modules, and the results indicated that these flipped classroom teaching modules considerably enhanced students' ability of solving mathematical problems related with the teaching modules. In addition, the flipped classroom model enhanced students' performance levels and skills in Mathematics. Surveys also showed that students' experience became more positive with the flipped classroom model as they became more familiar with this new teaching approach. Students indicated that they spent more time in the flipped-class teaching format. The flipped classroom increases students' responsibility for their own learning, they have to learn how to manage their time working with the online course, developing self-study and autonomous learning skills.

Future research needs to be conducted to more effectively compare student outcomes with courses which use different teaching methods.

\section{REFERENCES}

[1] Bergmann, J., \& Sams, A. (2012). Flip Your Classroom: Reach Every Student in Every Class Every Day. Arlington: ISTE.

[2] Findlay-Thompson, S., \& Mombourquette, P. (2014). Evaluation of a flipped classroom in an undergraduate business course. Business Education and Accreditation, 6, 63-71.

[3] Bergmann, J., Overmyer, J., \& Wilie, B. (2013, July 9). The Flipped class: Myths versus reality [Web log post]. Retrieved from http://www.thedailyriff.com/articles/the-flipped-classconversation-689.php

[4] Chen, Y., Wang, Y., Kinshuk, \& Chen, N. S. (2014). Is FLIP enough? or should we use the FLIPPED model instead? Computers and Education, 79, 16-27. doi:10.1016/j.compedu.2014.07.004

[5] Fautch, J. M. (2015). The Flipped classroom for teaching organic chemistry in small classes: Is it effective? Chemistry Education Research and Practice, 16(1), 179-186. doi:10.1039/c4rp00230j

[6] Lopes, A. P., Soares, F., (2016). "Video Lectures and Online Activities to Engage Students in a Flipped Classroom". 8th Annual International Conference on Education and New Learning Technologies EDULEARN16 Proceedings, Pages: 8688-8695, ISBN: 978-84-608-8860-4, ISSN: 2340-1117, doi: 10.21125/edulearn.2016.0890

[7] O'Flaherty, J., \& Phillips, C. (2015). The use of flipped classrooms in higher education: a scoping review. The Internet and Higher Education, 25, 85-95.

[8] Davies, R. S., Dean, D. L., \& Ball, N. (2013). Flipping the classroom and instructional technology integration in a college-level information systems spreadsheet course. Educational Technology Research and Development, 61, 563-580. doi:10.1007/s11423-013-9305-6

[9] Lopes, A.P. \& Soares, F. (2018). Perception and performance in a flipped Financial Mathematics classroom. The International Journal of Management Education, vol: 16 (1) pp: 105-113. ISSN: 14728117. DOI: 10.1016/j.ijme.2018.01.001

[10] Milheim, W. D. (2006). Strategies for the Design and Delivery of Blended Learning Courses. Educational Technology, 46(6), 120-137.

[11] Anohina, A. (2005). Analysis of the terminology used in the field of virtual learning. Educational Technology and Society, 8(3), 91-102. 
[12] Bonk, C.J., and C.R. Graham (2006). The Handbook of Blended Learning: Global Perspectives, Local Designs. Pfeiffer Publishing, San Francisco, CA, USA.

[13] Blended Learning Universe (2017). Retrieved from https://www.blendedlearning.org/basics/

[14] DeLozier, S. J., \& Rhodes, M. G. (2016). Flipped classrooms: A review of key ideas and recommendations for practice. Educational Psychology Review, 1-11.

[15] Flipped Learning Network. (2014). What is flipped learning?. Retrieved from http://flippedlearning.org/wp-content/uploads/2016/07/FLIP_handout_FNL_Web.pdf

[16] Bishop, J. L., \& Verleger, M. A. (2013). The flipped classroom: A survey of the research. In 120th ASEE national conference and exposition, Atlanta, GA (paper ID 6219). Washington, DC: American Society for Engineering Education.

[17] Dove, A., \& Dove, E. (2015). Examining the influence of a flipped mathematics course on preservice elementary teachers' mathematics anxiety and achievement. Electronic Journal of Mathematics \& Technology, 9(2), 166-179.

[18] Guerrero, S., Beal, M., Lamb, C., Sonderegger, D., \& Baumgartel, D. (2015). Flipping undergraduate finite mathematics: Findings and implications. PRIMUS, 25(9-10), 814-832.

[19] Larsen, J. (2015). Adult students' experiences of a flipped mathematics classroom. Adults Learning Mathematics, 10(1), 50-67.

[20] Bloom, B. S. (Ed.) (1956). Taxonomy of educational objectives: The classification of educational goals: Handbook I, cognitive domain. New York: Longman.

[21] Anderson, L. W., \& Krathwohl, D. (Eds.) (2001). A taxonomy for learning, teaching and assessing: A revision of Bloom's taxonomy of educational objectives. New York: Longman.

[22] Stanislav, V. (2013). Online Problems for Mathematics and Computer Science Education. Retrieved from $h$ ttp://is.muni.cz/th/373843/fi_b/thesis.pdf

[23] Torres, C., Lopes, A.P., Babo, L., Azevedo, J., (2017). MatActiva Project - A mathematical dynamic environment to engage students in the learning process. The e-Learning Excellence Awards 2017: An Anthology of Case Histories. Pages:125-138, ISBN: 978-1-911218-58-6. Academic Conferences and Publishing International Limited.

[24] Lopes, A. P., Babo, L. and Torres, C. (2015). The Impact of an Online Mathematics Education Project (MatActiva) on Higher Education Students. Proceedings of 9th International Technology, Education and Development Conference - INTED2015, March 2015, Madrid, Spain, Pages: 2921-2927, ISBN: 978-84-606-5763-7, ISSN: 2340-1079.

[25] Lopes, A.P., Babo, L., Azevedo, J., Torres, C., (2017). "Data Analysis and Learning Analytics for Measure Effects of Gamification in a Math Online Project". In 11th International Technology, Education and Development Conference - INTED2017 Proceedings, 6th-8th March 2017, Valencia, Spain, Pages: 8052-8062, ISBN: 978-84-617-8491-2, ISSN: 2340-1079, doi: 10.21125/inted.2017.1896

[26] Lopes, A.P., Soares, F., (2017). "Flipped Classroom With a MOOC" An E-Learning Model into a Mathematics Course. In 11th International Technology, Education and Development Conference - INTED2017 Proceedings, 6th-8th March 2017, Valencia, Spain, Pages: 46434649, ISBN: 978-84-617-8491-2, ISSN: 2340-1079, doi: 10.21125/inted.2017.1092

[27] Lopes, A. P., Soares, F., (2016). "Video Lectures and Online Activities to Engage Students in a Flipped Classroom". In 8th Annual International Conference on Education and New Learning Technologies EDULEARN16 Proceedings, Barcelona (Spain) on the 4th, 5th and 6th of July, 2016. Pages: 8688-8695, ISBN: 978-84-608-8860-4, ISSN: 2340-1117, doi: 10.21125/edulearn.2016.0890

[28] Soares, F., Lopes, A. P., (2016). "Teaching Mathematics Using Massive Open Online Courses". In 10th International Technology, Education and Development Conference - INTED2016 Proceedings, $7^{\text {th }}-9^{\text {th }}$ March 2016, Valencia, Spain, Pages: 2635-2641, ISBN: 978-84-608-56177, ISSN: 2340-1079, doi: 10.21125/inted.2016.1563

[29] "M100S," YouTube. [Online]. Accessed 10 January, 2018. Available:https://www.youtube.com/channel/UCwNMLB6X3VJG7da6hXI4kiw 